\title{
Does Earnings Management Affect the Cost Stickiness of Corporate?
}

\author{
Yusi Jin \\ School of Management, Wuhan University of Technology, Wuhan 430070, China \\ 616695696@qq.com
}

Keywords: Earnings management; Total cost stickiness; Sales management costs stickiness; Cost management

\begin{abstract}
In recent years, many scholars have found that there is a sticky phenomenon in the cost of enterprises. However, due to the special securities access and supervision system in China, it is necessary to adjust the cost of the enterprise to achieve a certain level of profitability through real earnings management and accrual earnings management. Based on the analysis of the financial data of 1912 Shanghai and Shenzhen A-share listed companies from 2011 to 2015, this paper examines whether the earnings management motivations of listed companies in China are affected and how they affect the cost of enterprises. The results show that the motivation of earnings management has a significant impact on the overall cost and cost of listed companies in China. " take a bath" motive will increase the cost of listed companies sticky cost, turnaround motive will weaken the cost of listed companies sticky cost. This paper studies the cost of corporate stickiness from the perspective of earnings management, which can help managers to estimate the cost of corporate stickiness more accurately, so as to make more correct management and decision-making and promote the improvement of enterprise performance.
\end{abstract}

\section{Introduction}

As an important concept of cost and management accounting, cost habits refer to the relationship between the change in total cost of business and its business volume. In the traditional model of cost habits, the relationship between cost and its business volume is linear, that is, the cost is symmetric as the volume of business increases and decreases. According to this traditional model of cost habits, the cost of the enterprise is only mechanically changing with the current business volume, and the manager does not have the active cost management behavior [1]. However, Cooper, Noreen et al. Argue that this traditional model does not correspond to the practice of cost management in the real manager, and that the cost management behavior of the manager will increase the cost when the amount of business increases is greater than the decrease in the volume of business, That is, the cost increases and decreases with the amount of business is not symmetrical. Anderson et al (hereinafter referred to as $\mathrm{ABJ}$ ) borrows the concept of price stickiness proposed by Hamermesh et al., Which increases the rate of increase in business volume when the amount of business increases is greater than the rate of decrease in traffic, this is called Cost Stickiness [2,3]. On the basis of this, ABJ takes the sales and management expenses (SG \& A) of American public companies as the research object. For the first time through a large sample empirical test confirmed that there is a problem of cost stickiness in American public companies [4,5].

Although domestic and foreign scholars have shown that there is a sticky phenomenon in the cost of enterprises, but because of China's special securities access and regulatory system, will enable listed companies in order to achieve a certain purpose (Such as issuing shares, turning losses, insider trading, manipulating the market ) for earnings management. Enterprises may adjust the cost 
of the enterprise to achieve a certain level of profitability through real earnings management and accrual earnings management. Management's deliberate adjustment of the cost of the business may overestimate or underestimate the cost of the enterprise. Then the cost of stickiness based on the traditional model is likely to be affected by earnings management. This paper is based on this idea to study the management of earnings management behavior will affect the cost stickiness of the enterprise? Whether there is a difference in the impact of earnings management on the cost of corporate cost? And how does earnings management affect cost stickiness?

\section{The Literature Review and Research Hypothesis}

China's regulatory system for listed companies is more stringent, which makes the capital market motive becomes the main motive of earnings management. China Securities Regulatory Commission, listed companies for two consecutive years of losses will be known as the "ST" mark, listed companies for three consecutive years of losses will face delisting. In order to remove the "ST" mark, or in order to avoid delisting, these companies tend to take the "big bath" of the earnings management, they will increase the cost of losses that year, so as to create a favorable condition for the next year's profitability. Usually they will be bad debts, backlog of inventory and other assets of the loss included in the year, you can also be a variety of handling costs included in the year. So that the cost of the enterprise that year will be further expanded, the loss of corporate cost costs will appear significant sticky characteristics, making the overall cost of listed companies increased viscosity. Turnaround motive means that the enterprise will be as much as possible income, less cost in the realization of profitability of the year, which will reduce the level of cost stickiness of this year, so that the overall cost stickiness level of listed companies will be reduced.

J.Q. Lu (1999) through the study found that China's listed companies in order to avoid delisting, will be down in the loss of earnings management adjustments, and be upward earnings management to adjust in the year of turning losses. So that the loss of the cost of the year the cost of sticky will increase, and the loss turning of the company's cost of the year will reduce the cost stickiness [6]. Kama and Weiss (2010) analyzed the financial data of US listed companies and found that when some companies were losing money or earnings continued to decline, managers would have to avoid loss of earnings management motivation, the cost will be a lot of reductions. So as to reduce the loss or to achieve the purpose of profit, this will make the company's cost to reduce the viscosity, or even anti-sticky phenomenon. L. Chen et al. (2012) analyzed the financial data of listed companies from 1994 to 2008 to see whether the management's earnings manipulation will have an impact on the estimation of corporate cost stickiness [7]. As China's securities regulatory system is more stringent, listed companies for three consecutive years of losses will face the risk of delisting, when the listed company losses, the enterprise managers will take the "big bath" of the earnings management, to try to increase Loss of the cost of the current year, so as to provide space for the next year's earnings management, so this will make the "big bath" when the cost of the phenomenon of overvalued phenomenon, the overall cost of listed companies will be subject to the cost of " take a bath " surplus Motivation of the impact.

Therefore, we believe that listed companies in the loss of the year will appear " take a bath " behavior, downward earnings management, so that the loss of the company's " take a bath " behavior will increase the overall stickiness level of China's listed companies, then will be upward earnings management in the year of turning losses, which will weaken the overall stickiness level of China's listed companies. Based on the above analysis, we propose the following assumptions:

H1: enterprises "take a bath" motive will enhance the overall cost of the listed company's total viscosity level; turnaround motivation will weaken the total cost of listed companies sticky level; 
H2: enterprises "take a bath" move will enhance the overall sales management costs of listed companies sticky level; turnaround motivation will weaken the sales management costs of listed companies sticky level.

\section{Research Design}

Sample Selection. This paper chooses the companies listed in Shanghai and Shenzhen Stocks to study the financial statements of these companies from 2011 to 2015 as the sample data, and through empirical analysis, whether earnings management will affect the estimation of the cost of listed companies. This paper selects companies listed prior to 2011 and uses the following criteria to screen for samples:

a: As the financial and insurance industry and other industry operating characteristics are quite different, so this article will be excluded from the financial and insurance industry data;

b: Excluding 2011 to 2015 by the SFC ST, * ST and PT listed companies;

c: Remove the obvious error or data anomalies of the sample, such as the total asset value is zero or negative;

$\mathrm{d}$ : Eliminate data in the sample that is missing or less than two consecutive years.

Through the above screening, a total of 1912 companies, a total of 9539 sample data. The data used in this paper is from the CSMAR database. The data distribution of each industry is shown in Table 1, and the software STATA is used to analyze the samples.

Table 1 Sample industry distribution table

\begin{tabular}{c|c|c}
\hline Industry type & $\begin{array}{c}\text { Number of } \\
\text { samples }\end{array}$ & proportion \\
\hline real estate & 167 & $8.73 \%$ \\
\hline industry & 1289 & $67.42 \%$ \\
\hline Utilities & 252 & $13.18 \%$ \\
\hline business & 136 & $7.11 \%$ \\
\hline Integrated & 68 & $3.56 \%$ \\
\hline total & 1912 & $100 \%$ \\
\hline
\end{tabular}

The definition of research variables. In the selection of cost variables, many scholars in the study shows that sales management costs and total operating costs exists sticky phenomenon, which is an important way of earnings management. Due to the difference of the data selected by different companies in different periods, take the natural logarithm can eliminate a certain heteroskedasticity, this paper takes the logarithm of the change rate of sales management cost and the change rate of total operating costs as the substitution variable.

In the selection of business variables, As the measurement of changes in business volume is more cumbersome, and the main business income changes and business volume changes have a direct relationship with the main business income changes which can also be more objective to reflect the changes in business volume, and its data can From the company's financial statements directly to obtain, so in this study I will replace the business volume changes with the main business income rate of change.

In the selection of earnings management motivational variables, in this paper, the setting of the motivational variables of the earnings management mainly takes into account "take a bath" motive 
and turnaround motive, as shown in Table 2:

Table 2 Definition and description of variables

\begin{tabular}{|c|c|c|}
\hline Variable name & $\begin{array}{l}\text { Variable } \\
\text { symbol }\end{array}$ & Variable definitions \\
\hline $\begin{array}{c}\text { Total cost of } \\
\text { business growth }\end{array}$ & $\ln \frac{T C E_{i, t}}{T C E_{i, t-1}}$ & $\begin{array}{l}\text { Ln (Total cost of business this year / The total } \\
\text { cost of the previous year) }\end{array}$ \\
\hline $\begin{array}{l}\text { Sales management } \\
\text { costs growth rate }\end{array}$ & $\ln \frac{\mathrm{SG} \& A_{i, t}}{\mathrm{SG} \& A_{i, t-1}}$ & $\begin{array}{l}\text { Ln (sales management costs this year / sales } \\
\text { management costs of the previous year) }\end{array}$ \\
\hline $\begin{array}{l}\text { Main business } \\
\text { income growth rate }\end{array}$ & $\ln \frac{\operatorname{Rev} v_{i, t}}{\operatorname{Rev} v_{i, t-1}}$ & $\begin{array}{l}\text { Ln (Main business income this year / Main } \\
\text { business income of the previous year) }\end{array}$ \\
\hline Dummy variable & $d_{i, t}$ & $\begin{array}{c}\text { If the listed company in the first phase of } \\
\text { operating income less than } \mathrm{t}-1 \text { period to take } 1 \text {; } \\
\text { otherwise } 0\end{array}$ \\
\hline $\begin{array}{l}\text { "Take a bath" } \\
\text { motive }\end{array}$ & $\mathrm{B} I G B A T H_{i, t}$ & $\begin{array}{l}\text { If the listed company that year loss, that is, net } \\
\text { profit is less than zero, the value of } 1 \text {; otherwise } \\
0\end{array}$ \\
\hline Turnaround motive & $\operatorname{LoSS}_{i, t}$ & $\begin{array}{l}\text { If the listed company profit and loss of the } \\
\text { previous year, the value of } 1 \text {; otherwise } 0\end{array}$ \\
\hline
\end{tabular}

Model Design. This article mainly uses the univariate factors to analyze the effect of "take a bath" motive and turnaround motive on the cost stickiness of the listed companies in China (Eq.1, Eq.2, Eq.4, Eq.5). And then use the multiple linear regression model to test the two kinds of earnings management motivation on the cost of the common effect of sticky (Eq.3, Eq.6).

$$
\ln \frac{\operatorname{SGR} A_{i, t}}{\operatorname{SGR} A_{i, t-1}}=\beta_{0}+\beta_{1} \times \ln \frac{\operatorname{Rev}_{i, t}}{\operatorname{Rev}_{i, t-1}}+\beta_{2} \times d_{i, t} \times \ln \frac{\operatorname{Rev}_{i, t}}{\operatorname{Rev} v_{i, t-1}}+\beta_{3} \times d_{i, t} \times \ln \frac{\operatorname{Rev}_{i, t}}{\operatorname{Rev} v_{i, t-1}} \times B I G B A T H_{i, t}+\varepsilon_{i, t}
$$

$\beta_{0}$ is a constant term;

$\beta_{1}$ represents the percentage increase in sales management costs (total operating costs) when revenue is increased by $1 \%$;

$\beta_{2}$ represents the viscosity coefficient of Sales management costs (total operating cost);

$\beta_{3}$ indicates the effect of "take a bath" motive on cost stickiness;

$\varepsilon_{i, t}$ denotes a random error term.

When the return of the sample, when the company does not appear "take a bath" motive, the part 
containing the dummy variable"BIGBATH $H_{i, t}$ " is 0 , Then the regression result is still operating income increased by $1 \%$, sales management costs increased by $\beta_{1} \%$, the operating income is reduced by $1 \%$ and the sales management costs are reduced $\left(\beta_{1}+\beta_{2}\right) \%$; When the company appears "take a bath" motive, the part containing the dummy variable "BIGBAT $H_{i, t}$ " is 1 , and the regression results indicate that the operating income increased by $1 \%$, sales management costs increased by $\beta_{1} \%$, the operating income is reduced by $1 \%$ and the sales management costs are reduced $\left(\beta_{1}+\beta_{2}+\beta_{3}\right) \%$; if the " take a bath " motive has a downward regulation on cost stickiness, $\left(\beta_{1}+\beta_{2}+\beta_{3}\right)<\left(\beta_{1}+\beta_{2}\right)$, further deduced $\beta_{3}<0$, and the smaller the value of $\beta_{3}$, the greater effect of " take a bath " motive on the increase in cost stickiness.

$$
\ln \frac{\operatorname{SGR} A_{i, t}}{\operatorname{SGR} A_{i, t-1}}=\beta_{0}+\beta_{1} \times \ln \frac{\operatorname{Rev}_{i, t}}{\operatorname{Rev} v_{i, t-1}}+\beta_{2} \times d_{i, t} \times \ln \frac{R \theta v_{i, t}}{\operatorname{Rev} v_{i, t-1}}+\beta_{4} \times d_{i, t} \times \ln \frac{R \theta v_{i, t}}{\operatorname{Rev} v_{i, t-1}} \times \operatorname{LOSS}_{i, t}+\varepsilon_{i, t}
$$

$\beta_{4}$ indicates the effect of turnaround motive on cost stickiness;

When the regression is returned to the sample, the part of the dummy variable "LOSS when the company does not appear turnaround motive, and the result of this regression is still operating income increased by $1 \%$, sales management costs increased by $\beta_{1} \%$, the operating income is reduced by $1 \%$ and the sales management costs are reduced $\left(\beta_{1}+\beta_{2}\right) \%$; When the company appears turnaround motive, the part containing the dummy variable "LOSS $i, t$ is 1 , and the regression results indicate that the operating income increased by $1 \%$, sales management costs increased by $\beta_{1} \%$, the operating income is reduced by $1 \%$ and the sales management costs are reduced $\left(\beta_{1}+\beta_{2}+\beta_{4}\right) \%$; if the turnaround motive has an upward regulation on cost stickiness , $\left(\beta_{1}+\beta_{2}+\beta_{4}\right)>\left(\beta_{1}+\beta_{2}\right)$, and further deduce $\beta_{4}>0$, and the greater the value of $\beta_{4}$, The greater the weakening effect of turnaround motive on cost stickiness.

$$
\begin{aligned}
& \ln \frac{\operatorname{SGR} A_{i, t}}{\operatorname{SGR} A_{i, t-1}}=\beta_{0}+\beta_{1} \times \ln \frac{R \theta v_{i, t}}{\operatorname{Rev} v_{i, t-1}}+\beta_{2} \times d_{i, t} \times \ln \frac{\operatorname{Rev}_{i, t}}{\operatorname{Rev}_{i, t-1}}+\beta_{3} \times d_{i, t} \times \ln \frac{\operatorname{Rev}_{i, t}}{\operatorname{Rev} v_{i, t-1}} \times B I G B A T H_{i, t}+\beta_{4} \times d_{i, t} \times \\
& \ln \frac{\operatorname{Rev} v_{i, t}}{\operatorname{Rev} v_{i, t-1}} \times \operatorname{LOSS}_{i, t}+\varepsilon_{i, t}
\end{aligned}
$$


When the regression is returned to the sample, the part of the dummy variable "BIGBAT $H_{i, t}$ " and "LOSS ${ }_{i, t}$ " is 0 when the company does not appear "take a bath" motive and turnaround motive, and the result of this regression is still operating income increased by $1 \%$, sales management costs increased by $\beta_{1} \%$, the operating income is reduced by $1 \%$ and the sales management costs are reduced $\left(\beta_{1}+\beta_{2}\right) \%$; When the company appears "take a bath" motive, the part containing the dummy variable "BIGBATH $H_{i, t}$ " is 1 , and the part of "LOSS ${ }_{i, t}$ " is still 0 , and the regression results indicate that the operating income increased by $1 \%$, sales management costs increased by $\beta_{1} \%$, the operating income is reduced by $1 \%$ and the sales management costs are reduced $\left(\beta_{1}+\beta_{2}+\beta_{3}\right) \%$; When the company appears turnaround motive, the part containing the dummy variable "LOSS 1, and the part of "BIGBATH $H_{i, t}$ " is 0 , and the regression results indicate that the operating income increased by $1 \%$, sales management costs increased by $\beta_{1} \%$, the operating income is reduced by $1 \%$ and the sales management costs are reduced $\left(\beta_{1}+\beta_{2}+\beta_{4}\right) \%$. By analyzing the common effects of the two motivations on cost stickiness, the test conclusions are consistent with the previous univariate analysis model.

$$
\begin{aligned}
& \ln \frac{T C E_{i, t}}{T C E_{i, t-1}}=\beta_{0}+\beta_{1} \times \ln \frac{R \theta v_{i, t}}{R \theta v_{i, t-1}}+\beta_{2} \times d_{i, t} \times \ln \frac{\operatorname{Rev} v_{i, t}}{R \theta v_{i, t-1}}+\beta_{3} \times d_{i, t} \times \ln \frac{\operatorname{Rev}_{i, t}}{\operatorname{Rev} v_{i, t-1}} \times B I G B A T H_{i, t}+\varepsilon_{i, t} \\
& \ln \frac{T C E_{i, t}}{T C E_{i, t-1}}=\beta_{0}+\beta_{1} \times \ln \frac{\operatorname{Rev}_{i, t}}{\operatorname{Rev} v_{i, t-1}}+\beta_{2} \times d_{i, t} \times \ln \frac{\operatorname{Rev}_{i, t}}{\operatorname{Rev} v_{i, t-1}}+\beta_{4} \times d_{i, t} \times \ln \frac{\operatorname{Rev}_{i, t}}{\operatorname{Rev} v_{i, t-1}} \times \operatorname{LOSS}_{i, t}+\varepsilon_{i, t} \\
& \ln \frac{T C E_{i, t}}{T C E_{i, t-1}}=\beta_{0}+\beta_{1} \times \ln \frac{R \theta v_{i, t}}{\operatorname{Rev} v_{i, t-1}}+\beta_{2} \times d_{i, t} \times \ln \frac{\operatorname{Rev} v_{i, t}}{\operatorname{Rev} v_{i, t-1}}+\beta_{3} \times d_{i, t} \times \ln \frac{\operatorname{Rev} v_{i, t}}{\operatorname{Rev} v_{i, t-1}} \times B I G B A T H_{i, t}+\beta_{4} \times d_{i, t} \times \\
& \ln \frac{\operatorname{Rev}_{i, t}}{\operatorname{Rev} v_{i, t-1}} \times \operatorname{LOSS}_{i, t}+\varepsilon_{i, t}
\end{aligned}
$$

Similar to models Eq.1, Eq.2, Eq.3, models Eq.4, Eq.5, Eq.6 are used to test whether "take a bath" motive and turnaround motive the two kinds of earnings management motives have an effect on cost stickiness. If $\beta_{3}<0$, it is inferred that "take a bath" motive has a stronger effect on cost stickiness, and the smaller the value of $\beta_{3}$, the greater effect of " take a bath " motive on the 
increase in cost stickiness; If $\beta_{4}>0$, it is inferred that turnaround motive has a weakening effect on cost stickiness, and the greater the value of $\beta_{4}$, The greater the weakening effect of turnaround motive on cost stickiness.

\section{The Empirical Test and Analysis of the Results}

Descriptive Statistics. See Table 3, which provides a descriptive statistic of the main variables. It can be seen from Table 3 that the average of total cost of business growth rate $\left(\ln \frac{T C E_{i_{z} t}}{T C E_{i_{t} t-1}}\right)$ is 0.135 , and the average of sales management costs growth rate $\left(\ln \frac{\operatorname{SG} \& A_{i, t}}{\operatorname{SG} \& A_{i, t-1}}\right)$ is 0.116 , the average of main business income growth rate $\left(\ln \frac{R \theta v_{i, t}}{R e v_{i, t-1}}\right)$ is 0.105 , which is in line with the development status of China's industry.

Table 3 Descriptive statistics of the main variables

\begin{tabular}{c|c|c|c|c|c}
\hline Variable & $\mathrm{N}$ & Mean & $\mathrm{SD}$ & Min & Max \\
\hline $\ln \frac{T C E_{i, t}}{T C E_{i, t-1}}$ & 9539 & 0.135 & 0.243 & -0.627 & 1.361 \\
\hline $\ln \frac{\mathrm{SG} \& A_{i, t}}{\mathrm{SG} \& A_{i, t-1}}$ & 9539 & 0.116 & 0.309 & -0.887 & 1.783 \\
\hline $\ln \frac{\operatorname{Rev} v_{i, t}}{\operatorname{Rev} v_{i, t}-1}$ & 9539 & 0.105 & 0.345 & -1.006 & 2.219 \\
\hline$d_{i, t}$ & 9539 & 0.323 & 0.467 & 0 & 1 \\
\hline BIGBATH & 9539 & 0.103 & 0.304 & 0 & 1 \\
\hline LOSS $_{i, t}$ & 9539 & 0.065 & 0.246 & 0 & 1 \\
\hline
\end{tabular}

Regression Analysis. Using Eq.1, Eq.2, Eq.3, Eq.4, Eq.5 and Eq.6 to verify whether "take a bath" motive and turnaround motive have an effect on cost stickiness, the test results are shown in Table 4: 
Table 4 Regression Results on the Impact of Earnings Management on the Existence of Cost Costs in China 's Listed Companies

\begin{tabular}{|c|c|c|c|c|c|}
\hline $\begin{array}{l}\text { Sticky } \\
\text { category }\end{array}$ & $\begin{array}{l}\text { Stat- } \\
\text { istics }\end{array}$ & $\begin{array}{l}\text { No earnings } \\
\text { management } \\
\text { variables } \\
\text { added }\end{array}$ & $\begin{array}{l}\text { Add "take a } \\
\text { bath" variable } \\
\text { (Eq.1, Eq.4) }\end{array}$ & $\begin{array}{l}\text { Add } \\
\text { turnaround } \\
\text { variable } \\
(\text { Eq.2,Eq.5) }\end{array}$ & $\begin{array}{l}\text { At the same } \\
\text { time add "take } \\
\text { a bath" and } \\
\text { turnaround } \\
\text { variables } \\
\text { (Eq.3, Eq.6) }\end{array}$ \\
\hline \multirow{5}{*}{$\begin{array}{l}\text { Sales } \\
\text { management } \\
\text { costs of } \\
\text { stickiness }\end{array}$} & $\beta_{0}$ & $0.067 * * *$ & $0.068 * * *$ & $0.068 * * *$ & $0.069 * * *$ \\
\hline & $\beta_{1}$ & $0.433 * * *$ & $0.430 * * *$ & $0.433 * * *$ & $0.430 * * *$ \\
\hline & $\beta_{2}$ & $-0.345 * * *$ & $-0.233 * * *$ & $-0.377 * * *$ & $-0.278 * * *$ \\
\hline & $\beta_{3}$ & $\longrightarrow$ & $-0.352 * * *$ & 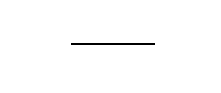 & $-0.282 * * *$ \\
\hline & $\beta_{4}$ & - & $\longrightarrow$ & $0.716^{* *}$ & $0.500^{*}$ \\
\hline \multirow{5}{*}{$\begin{array}{l}\text { Total cost of } \\
\text { stickiness }\end{array}$} & $\beta_{0}$ & $0.026^{* * *}$ & $0.028 * * *$ & $0.027 * * *$ & $0.028 * * *$ \\
\hline & $\beta_{1}$ & $0.815^{* * *}$ & $0.810 * * *$ & $0.815^{* * *}$ & $0.811^{* * *}$ \\
\hline & $\beta_{2}$ & $-0.073 * * *$ & $0.107 * * *$ & $-0.109 * * *$ & $0.068 * * *$ \\
\hline & $\beta_{3}$ & 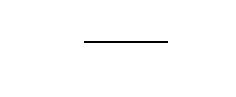 & $-0.564 * * *$ & $\longrightarrow$ & $-0.503 * * *$ \\
\hline & $\beta_{4}$ & 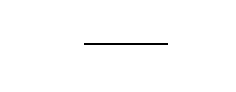 & 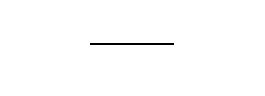 & $0.826^{* * *}$ & $0.438 * * *$ \\
\hline
\end{tabular}

Note: $* * *, * *$ and $*$ indicate that the regression coefficients are significant at $1 \%, 5 \%$ and $10 \%$ respectively.

"Take a bath" motive will increase the sales management costs of stickiness of listed companies, turnaround motive will weaken the sales management costs of stickiness of listed companies. For the sales management costs, For the model to add the " take a bath " factor, the value of $\beta_{3}$ is -0.352, and the coefficient is shown to be negative, indicating that part of the stickiness of sales management costs is due to the " take a bath " factor, and " take a bath " motive has a downward regulation on cost stickiness ; For the model to add turnaround factor, the value of $\beta_{4}$ is 0.716 , and the coefficient is positive, which indicates that the turnaround factor has a reverse adjustment effect on the sales management costs of stickiness. For the model to add "take a bath" factor and turnaround factor at the same time, the value of $\beta_{3}$ and $\beta_{4}$ is -0.282 and 0.500 , respectively, which is consistent with the sign of the previous single factor model, and further proves that the " take a bath" factor will increase the sales management costs of stickiness, turnaround factors will reduce the sales management costs of stickiness. 
"Take a bath" move will increase the total cost of stickiness of listed companies, turnaround motive will weaken the total cost of stickiness of listed companies. For the total cost, the value of $\beta_{3}$ is -0.564 for the model that adds the " take a bath " factor, and the coefficient is negative, indicating that the total cost of stickiness is partly due to the " take a bath " factor, and " take a bath " motive has a downward regulation on cost stickiness; For the model to add turnaround factor, the value of $\beta_{4}$ is 0.826 , and the coefficient is positive, indicating that the turnaround factor has a reverse adjustment effect on the total cost of stickiness. For the model to add "take a bath" factor and turnaround factor at the same time, the values of $\beta_{3}$ and $\beta_{4}$ are -0.503 and 0.438 , respectively, consistent with the notation of the previous single factor model coefficients, which further proves that the " take a bath" factor will increase the total cost of stickiness, turnaround factors will reduce the total cost of stickiness.

\section{To Further Discuss the Analysis and Robustness Test}

Anderson (2003) study demonstrated that cost stickiness would be reversed with the extension of time. China's listed companies in order to avoid delisting, will be down in the loss of earnings management adjustments, and be upward earnings management to adjust in the year of turning losses. With the extension of the time horizon, the impact of earnings management motivation on cost stickiness of each period will be different. We believe that the enterprise's "take a bath" motive has an enhanced effect on cost stickiness of the listed companies in the future period, turnaround motive will weaken cost stickiness of it. In this paper, we propose the following assumptions:

H1: the company's "take a bath" motive will enhance the total cost of stickiness of the listed companies in the future period, turnaround motive will weaken the total cost of stickiness of the listed companies in the future period.

H2: the company's "take a bath" motive will enhance the sales management costs of stickiness of the listed companies in the future period, turnaround motive will weaken the sales management costs of stickiness of the listed companies in the future period.

On the basis of the above-mentioned sample regression model, the time-spanning factors were added to verify the effect of earnings management on the cost reversal of cost stickiness, and the effects of "take a bath" motive and turnaround motive on cost stickiness of listed companies were compared respectively. This paper draws the following conclusions:

(1) Earnings management increases the level of sales management costs' stickiness for each period.

(2) Earnings management increases the level of total cost of stickiness for each period.

For the separate removal of "take a bath" motive and turnaround motive samples, the sales management costs in the future period have no obvious change in the trend, which is related to the company in "take a bath" or turnaround of the particularity of the year; and Compared with the whole sample, for the non-motive samples which "take a bath" motive and turnaround motive were decreased at the same time, the sales management costs of stickiness of each period has declined, With the increase of time span, there is a clear trend of decreasing.

For the separate removal of "take a bath" motive and turnaround motive samples, the total cost of stickiness in the future period have no obvious change in the trend, which is related to the company in "take a bath" or turnaround of the particularity of the year; and Compared with the whole sample, for the non-motive samples which "take a bath" motive and turnaround motive were decreased at 
the same time, the total cost of stickiness of each period are gone, which may indicate that China's listed companies as a whole does not exist the total cost of sticky phenomenon.

\section{Conclusion and Inspiration}

In making cost management decisions, managers' estimates based on traditional cost stickiness models may cause the company's cost stickiness to be over-estimated. This paper studies the cost stickiness of enterprises from the perspective of earnings management, which can help managers to better estimate the cost stickiness of enterprises, so as to better manage and control the cost of enterprises. This paper draws the following conclusions: After removing "take a bath" motive and turnaround motive, the listed companies in our country do not have the phenomenon of cost stickiness as a whole. After removing "take a bath" motive and turnaround motive, the listed companies in our country exists the phenomenon of the sales management costs of stickiness, but the viscosity is reduced. The total cost stickiness of listed companies in China does not exist inversion, but the sales management costs of stickiness exist.

Based on the characteristics of China's companies listed in Shanghai and Shenzhen Stocks, this paper analyzes and studies the stickiness of sales management costs and the total operating costs from the perspective of earnings management. However, due to personal experience and limited knowledge, the research of this paper still has some shortcomings: this article only on the Shanghai and Shenzhen stocks companies listed on the overall cost stickiness were studied, did not conduct a specific industry research, due to the particularity of the industry, there may be some discrepancies in cost stickiness in different industries. In this paper, the choice of earnings management motives, only selected the most representative of "take a bath" motive and turnaround motive, for other motives, there is no further study of other motives, and other motives may have some effect on cost stickiness.

\section{References}

[1] E. Noreen: Conditions under Which Activity-Based Cost Systems Provide Relevant Costs. Journal of Management Accounting Research. (1991) No.3, p.159-168.

[2] R. Cooper and R.S. Kaplan: Activity-based Systems: Measuring the Costs of Resource Usage. Accounting Horizons. Vol. 6 (1992) No.3, p.1-13.

[3] E. Noreen and N. Soderstrom: The Accuracy of Proportional Cost Models: Evidence from Hospital Service Departments. Review of Accounting Studies. Vol. 2 (1997) No. 1, p.89-114.

[4] M.C. Anderson, R.D. Banker and S.N. Janakiraman: Are Selling, General, and Administrative Costs 'Sticky'? Journal of Accounting Research. Vol. 41 (2003) No.1, p.47-63.

[5] D.S. Hamermesh and G.A. Pfann: Adjustment Costs in Factor Demand. Journal of Economic Literature. Vol. 34 (1996) No.3, p.1264-1292.

[6] J.Q. LU: Empirical Study on Earnings Management of Chinese Listed Companies, J. Journal of Accounting Research. (1999) No.9, p.25-35. (In Chinese)

[7] L. Chen, L. Song and D. Shi: Enterprise Cost of Sticky is Overrated? An Empirical Study Based on Chinese Listed Companies, J. China Accounting Review. (2012) No.1, p.3-16. (In Chinese)

[8] W. Jiang and Y.M. Hu: Enterprise Cost Stickiness: Literature Review and Prospect, J. Accounting Research. (2011) No.9, p.74-79. (In Chinese) 
[9] Z.F. Li, Z.Q. Dong and Y.J. Lian: Earnings Management of Earnings Project or Earnings Management of Real Activities? Based on China's 2007 income tax reform research, J. Management of the world. (2011) No.1, p.121-134. (In Chinese)

[10]C. Liu, S.S. Zhao and Q.Y. Tan: Technical constraints, real earnings management and cost stickiness, J. Finance and Accounting Monthly. (2015) No.33, p.16-20.(In Chinese) 